\title{
EDUCAÇÃO DO CAMPO: A CONTRIBUIÇÃO POLÍTICA E EDUCATIVA DA ASSOCIAÇÃO DE ESTUDOS, ORIENTAÇÕES E ASSISTÊNCIA RURAL - ASSESOAR ${ }^{1}$
}

\author{
Mariza Rotta ${ }^{2}$ \\ UNOCHAPECO / PUCPR \\ mzrotta@gmail.com \\ Lindomar Wessler Boneti ${ }^{3}$ \\ PUCPR \\ lindomar@boneti.com
}

\begin{abstract}
RESUMO
O texto permeia caminhos que levam à Região Sudoeste do Paraná, palco de questões conflituosas vinculadas à posse da terra, haja vista que as características geográficas da região sul propiciaram maior concentração de agricultores familiares em tais regiões. Em meio à ordem dos fatos, observa-se a configuração de um panorama que serviu de cenário para organização e estruturação da ASSESOAR. A entidade trabalha em prol do desenvolvimento e da permanência do homem do campo no campo, por meio de acordos, parcerias e planejamento com instituições não governamentais de ordem nacional e internacional, bem como com a comunidade local, universidades e instituições religiosas. A partir de um perfil multidisciplinar, a Assesoar visualiza proposta de formação pautada em novos delineamentos educativos para os povos do campo. Ela traduz, em sua perspectiva epistemológica e social, elementos essenciais para o processo de interpretação, além de contribuir para a compreensão de questões que constituem e transformam a realidade do campo.
\end{abstract}

Palavras-chave: ASSESOAR; educação do campo; articulações sociais.

\section{FIELD EDUCATION IN THE REGION OF THE SOUTHWEST PARANA: HISTORICAL ASPECTS OF POLITICAL AND EDUCATIONAL CONTRIBUTION OF ASSESSOAR}

\begin{abstract}
The writing permeates paths leading to the Southwest Region of Paraná, scene of conflicting issues linked to land ownership, given that the geography of the southern region provided a greater concentration of farmers in such regions. Amid the order of events, it is observed the configuration of a panorama that formed the backdrop for organizing and structuring of ASSESOAR. The entity works towards developing and maintaining of the man of the field, through agreements, partnerships and planning with non-governmental national and international institutions, as well as the local community, universities and religious institutions. Founded on a multidisciplinary profile, ASSESOAR visualizes a proposal of formation based on new educational designs for field people. It translates, into your epistemological and social perspective, essential elements for the interpretation process, besides contributing for understanding issues that constitute and transform the reality of the field.
\end{abstract}

Keywords: ASSESOAR; field education; social joints. 


\section{Introdução}

A Associação de Estudos, Orientações e Assistência Rural - ASSESOAR constituiu-se institucionalmente enquanto uma ONG e iniciou suas atividades no ano de 1966, no Município de Francisco Beltrão, Região Sudoeste do Paraná. Trata-se de uma entidade que ao longo da sua atuação na região, construiu legitimidade e identidade voltada as questões do desenvolvimento rural e à construção da identidade educacional voltada para o campo, enfatizando a temática do desenvolvimento regional. A ASSESOAR foi fundada pelo Padre belga Joseph Caeckelbergh e por um grupo ${ }^{4}$ de jovens agricultores católicos, inspirados na Doutrina Social da Igreja, especialmente pela Encíclica Mater et Magistra, escrita pelo Papa João XXIII em 1961 e pelo Concílio Vaticano II. Buscava-se, por meio da ação pastoral dos leigos, agir sobre a situação de abandono e precariedade de pequenos agricultores situados na região do Sudoeste do Paraná. A ASSESOAR contou inicialmente com o apoio da Igreja Católica belga. Posteriormente, recebeu ajuda com custeio financeiro, de profissionais liberais e comerciantes do Município de Francisco Beltrão, visando a qualificação de jovens leigos, para atuarem na formação e capacitação técnica dos pequenos agricultores da região.

Portanto, neste texto, evidenciam-se as bases históricas e a seara política, sobre as quais se arquitetou a construção de um perfil característico institucional dessa organização, definida desde 1966 como a organização não governamental mais representativa do Sudoeste do Paraná. Como instrumento metodológico da reconstrução do perfil característico desta instituição, centrou-se na busca da compreensão da valia que os elementos detêm para a formação do sujeito do campo da região.

Pode-se afirmar que parte da história da Região Sudoeste do Paraná está relacionada à atuação da ASSESOAR e à estruturação social desenvolvida por esta instituição junto ao homem do campo. Mesmo que a atuação dessa instituição situava-se numa região específica, almejou-se contribuir com o advento de uma articulação nacional em torno da implementação de políticas econômicas e de educação, focalizadas na permanência dos sujeitos no campo.

Em quase meio século de existência, a organização vem se transformando e incorporando enredos ao seu perfil ideológico, ora ressignificando ora alterando os conceitos na perspectiva de ajustar a sua atuação aos diferentes contextos sociais e políticos. Assim sendo, ao longo da sua história, esta instituição vem estabelecendo articulações com um expressivo número de influências ideológicas e teóricas na perspectiva de dar significado ao que ela compreende por alargamento de políticas de permanência do homem no campo, aliada a um projeto de educação integrada.

Entre as proposições desenvolvidas pela organização encontra-se o Projeto Vida na Roça - PVR, que representou a materialização da alteração no cenário local no que se refere à questão educacional no campo. Contando com a contribuição de instituições parceiras no que se refere à discussão da postura ideológica relacionada à educação no campo, buscou se afinar à ótica dos movimentos sociais locais

Esta articulação das tecituras consentiu à instituição a ampliação dos interlocutores, o fortalecimento da sua posição na região, bem como da ampliação de fontes de financiamentos, sendo de essencial importância, pois há a percepção interna que urge readequar o seu papel no espaço de atuação, cada momento mais disputado e complexo. A possibilidade de se reinventar constantemente diante das projeções de um futuro provável constitui marca da entidade, em consoante à "sintonia fina" de alterações qualitativas e 
quantitativas das organizações envolvidas e ao momento atual de forte engajamento dos movimentos populares.

\section{O contexto histórico da ASSESOAR e a sua contribuição política e educativa para a região do Sudoeste do Paraná}

A ASSESOAR ao se instituir passou a exercer papel de referência no contexto regional para as organizações que se mobilizavam em torno da mesma causa e articular a própria trajetória a um contexto de maior amplitude, em consonância com os resultados do processo de ocupação do Sudoeste do Paraná ocorrido a partir do final do século XIX. Esta ocupação se efetivou a partir da iniciativa do Governo Federal ${ }^{5}$ somente a partir de 1940, não com a finalidade de proteção dos primeiros habitantes da região, mas a de proteger a fronteira de invasões de argentinos e paraguaios.

A ASSESOAR, desde o início da sua trajetória, define-se como lugar e espaço de debate almejando a organização de alternativas de busca de melhorias para o homem do campo, visualizando a necessidade de desenvolvimento reflexivo sobre situações envolvendo o processo de ocupação da terra, processos educativos, questões religiosas, sindicais e políticas, além de vislumbrar possibilidades de estruturação do enfrentamento às demandas que surgem em face da ocupação da região.

Tal processo se inicia quando os colonos, recém-saídos do conflito da Revolta dos Posseiros $^{6}$ em busca de alternativas para defenderem a posse e a propriedade da terra, enfrentaram os primeiros impactos de implantação da Revolução $\operatorname{Verde}^{7}$ na região. Enquanto parceiros da ASSESOAR, os pequenos agricultores do Sudoeste do Paraná, passaram a refletir sobre alternativas que gerassem maior autonomia e menor submissão ao mercado capitalista.

$\mathrm{Na}$ busca do fortalecimento de um compromisso social e orientados pelo diagnóstico socioeconômico resultante da leitura ${ }^{8}$ da realidade local, regional e nacional, implementou-se a metodologia desenvolvida pelos Organismos Rurais de Ação Católica, especialmente a da Juventude Agrária Católica - JAC. A preocupação e o trabalho da JAC visavam o bem comum do meio rural, buscando alargar a percepção sobre o modelo de agricultura familiar na qual vinha se incorporando as características do perverso sistema da modernização americano e europeu.

Nesse aspecto se construiu uma postura defensiva e preservacionista do que ainda restava do ambiente ecológico original, ou seja, matas e solos preservados em sua fertilidade. No aspecto social, adotaram-se estratégias mais positivas, no sentido de promover a formação ${ }^{9}$ de lideranças, objetivando estimular a organização local das comunidades e assim o desenvolvimento da qualidade de vida. Para isto, adotou-se inicialmente, a organização pastoral e social por faixa etária, cabendo aos jovens atuantes na JAC desenvolverem atividades com crianças e adultos, e aos demais a inserção na vida política para além da comunidade, envolvendo-se, por exemplo, em organizações de interesse profissional, como foi o caso de Sindicatos de Trabalhadores na Agricultura. Adotava-se o esforço comum de estimular e construir práticas específicas a cada forma de organização que contribuíssem para atingir a missão que definia a identidade da ASSESOAR: "desenvolver um novo jeito de trabalhar e viver onde o solo e a natureza possam ser vistos e cuidados como um bem para as gerações futuras" (ASSESOAR, 1990).

Por conseguinte, a ASSESOAR desenvolvia ações pautadas em seu Estatuto (1997), dispostas nos Capítulo I que estabeleciam ações coletivas a se desenvolver: 
Art. $1^{\circ}$. Pela direta participação dos agricultores na associação através dos meios por ela promovidos.

Art. $\mathbf{2}^{\mathbf{0}}$. A educação e formação do homem do campo procurarão atingir a todas as faces que dizem respeito à sua personalidade moral, religiosa $\mathrm{e}$ social. (ASSESOAR, 1997)

Os fundamentos ora dispostos desencadearam e consolidaram as atividades pastorais e organizativas que a região demonstrava necessitar nesse período histórico. Assim, o atendimento aos agricultores era desenvolvido por educadores e técnicos que seguiam as concepções ${ }^{10}$ de desenvolvimento postulados pela organização, focando a participação coletiva com base nos princípios de solidariedade, união e incentivo para que os agricultores se organizassem de forma autônoma. Tal trabalho se desenvolvia por meio de reflexões e debates associando-os a questões práticas da vida profissional dos agricultores. (ASSESOAR, 1998a)

Nesse mesmo período os agricultores associados à ASSESSOAR passaram a sentir a necessidade de construir uma organização política mais determinante e, como eram em sua maioria católicos, motivados pelo episódio da revolta dos posseiros de 1947, reuniamse com padres belgas e os leigos atuantes da ASSESSOAR na perspectiva de terem acesso a uma maior informação política. $\mathrm{O}$ momento foi contundente à Igreja Católica por ser o órgão basilar na formação de uma ampla rede de contatos nas diversas comunidades que formavam a região, consolidando um discurso cristão unificador nesse meio. A partir de tal cenário a ASSESOAR iniciou a organização e a estruturação da atuação por meio do desenvolvimento de políticas de parcerias com agências financiadoras que lhe dariam maior capilaridade e sustentabilidade ${ }^{11}$ institucional.

Surge, então, um novo posicionamento sobre o estatuto de fundação da ASSESOAR: assumiria a presidência da organização alguém com conhecimento acadêmico de nível superior, que fosse seguidor dos rituais católicos. Diante deste novo posicionamento, em 1978 os colonos se mobilizaram e realizaram a maior assembleia da organização até então, com a finalidade de alterar o perfil de formação escolar das pessoas que viessem a assumir a presidência da instituição futuramente.

Este processo alterou a essência dessa organização, isto é, a sua base ideológica. A mudança ideológica refletiu-se nos rumos da ASSESOAR implementando assim novas concepções no campo na Região Sudoeste do Paraná. A busca pelo processo de politização em face ao enfraquecimento das políticas cristãs ${ }^{12}$ levaram a organização a pleitear disputas por direções sindicais e de cooperativas nos anos seguintes.

Assim sendo, a organização encontrou-se diante de inúmeras interfaces que estabeleciam a necessidade de um processo de introspecção como organização, para entender quais caminhos deviam delinear a trajetória ideológica, política e pragmática de desenvolvimento da Região Sudoeste do Paraná. Com isto ocorreu também, o rompimento entre o clero conservador e a ASSESOAR, justo no momento em que assume pela primeira vez um presidente representante dos agricultores, quebrando o ciclo de presidência da instituição até então ocupado por um padre e um profissional liberal.

Para Veronese (1998, p. 92), o momento consolidou o período que "transformou a instituição dos agricultores familiares da região em uma entidade de agricultores descapitalizados da região Sudoeste do Paraná".

Esse cenário se organizou a partir de determinantes teóricos e metodológicos de cunho marxista e cristão que permeava as conjunturas de educação e desenvolvimento local, ganhando corpo a partir das rupturas de concepção que a Assesoar vinha passando. Pela postura adotada acabou por gerar enfrentamento com a Igreja e, posteriormente, no início da década de 1980, a distanciar-se dos trabalhos pastorais da Igreja, direcionando 
suas atividades para os movimentos sociais ligados ao campo e não mais para a função de formadora pastoral da Igreja Católica.

A partir da ótica dos movimentos sociais e os da organização sindical, os colonos líderes desenvolveram consciência de esquerda, gerando dissensos às posições conservadoras dos profissionais liberais e religiosos. Ocorreram assim abandonos de cargos por alguns profissionais liberais que tiveram papel relevante na condução de atividades em prol da catequese familiar, de orientações básicas sobre gestão de pequenos empreendimentos rurais e de lutas por educação das novas gerações para o uso sustentável da terra.

A marca da orientação cristã dos padres belgas e a atuação dos profissionais liberais que possibilitaram à organização o suporte necessário para que se infiltrasse em todas as comunidades e paróquias da região estava impregnada. Mas, os princípios cristãos não se mostravam aptos a enfrentar as mudanças impostas pela interposição de processos tecnológicos para a modernização da agricultura o que desencadearia um enfrentamento no campo político (ASSESOAR, 1998, p. 8).

Nesse contexto a organização buscava rever seus princípios para enfrentar as condições reais que se apresentava aos agricultores diante das demandas de tecnologia e da necessidade de capital para investir nas propriedades. Ressalta-se, ainda, que os agricultores, em sua maioria, estavam despreparados para compreender as mudanças. Então, a organização se conscientizou do processo, contou mais uma vez com o auxílio dos padres belgas, desenvolveu cursos de assistência técnica e passou a ter atuação massiva em quase 30 municípios da região Sudoeste do Paraná, atingindo anualmente de 15 a 20 mil agricultores. Porém, devido à falta de estrutura de pessoal os atendimentos não conseguiram primar por qualidade e acabaram focando na linha de produção em quantidade.

Mesmo ciente de que o trabalho ocorria de forma precária e que o foco da política era barrar o desenvolvimento do processo de modernização da agricultura nessa região e aumentar a autonomia econômica e social dos agricultores, a instituição viu tomar corpo a denominada "revolução verde", por meio de políticas desenvolvimentistas fortes, as quais alteraram o modo como os colonos se articulavam com o mercado. E novos agentes como bancos, cooperativas, governo entre outros, se articularam, desestruturando as formas organizativas e associativas das comunidades locais.

$\mathrm{Na}$ busca de proposta que viesse contrapor-se contundentemente a esta política desenvolvimentista, a ASSESOAR buscou fomentar o olhar para a preservação ambiental e a diversificação da produção como forma de garantir autonomia à agricultura familiar. As mudanças no cenário aliadas aos embates internos da entidade trilham para a redefinição do campo de atuação que busca meios de intervenção e, sobretudo, de uma aproximação cada vez maior no que se refere às questões sociais envolvendo os agricultores num longo trabalho de conscientização política e educativa do homem do campo na região.

Iniciou-se, então, o desenvolvimento de uma rede de contatos com organizações nacionais que também se articulavam por lutas específicas no cenário nacional como forma de ampliar as bases de apoio e referência para os projetos que planejam desenvolver e para os novos desafios que se apresentam. Em meio ao pleito de parcerias políticas que contribuíssem para o fomento de suas iniciativas, a organização passou a estimular e assessorar a criação de uma rede de pequenas associações, sindicatos e cooperativas que atuavam na defesa e na organização do homem do campo.

Com a nova proposta, a organização passou, por meio do diálogo, a fomentar o surgimento de novas lideranças regionais e foi tomando novamente, lugar de destaque no processo de desenvolvimento regional. Assim, garantiu espaço de negociação com outras 
organizações quanto a um entendimento que reafirmava a necessidade de contribuir com a construção de propostas que contemplassem a qualificação de recursos humanos e metodologias para a produção de conhecimento originados na relação entre o saber científico e o saber prático.

Esta proposta almejava se constituir enquanto base para a busca da construção da cidadania no campo, pressupondo que o conhecimento se constrói num processo contínuo e participativo, onde todos ensinam e aprendem. Neste contexto ocorreu o lançamento da proposta do método 'ver julgar agir' utilizado pela Igreja Católica nas Campanhas da Fraternidade, com o intuito de evidenciar as contradições próprias de cada sociedade. A partir da apropriação do conhecimento e a partir da organização de classe como estratégia de visualização das contradições políticas que devem ser percebidas como base para o enfrentamento dos embates ideológicos necessários à organização da vida no campo, observou-se que o desenvolvimento regional, só seria possível por uma ação conjunta das diferentes organizações regionais de caráter popular e progressista.

\section{Parcerias econômicas e políticas de âmbito nacional e internacional}

Para galgar os objetivos e com base na necessidade de novas forças, no final da década de 80 a ASSESOAR, juntamente com a Conferência Nacional dos Bispos do Brasil - CNBB; a Comissão da Pastoral da Terra - CPT; a Central Única dos Trabalhadores CUT; o Movimento Sem Terra - MST e outras associações, buscou junto a um grupo de financiadores internacionais, apoio financeiro. Em face dessa necessidade, firmou com a Obra Episcopal da Igreja Católica da Alemanha para a Cooperação ao Desenvolvimento MISEREOR $^{13}$ - um projeto conhecido como Fundo de Crédito Rotativo - FCR - com objetivo de fomentar o associativismo que, em meados da década de 90, deu origem ao Sistema de Cooperativas de Crédito Rural com Intenção Solidária - CRESOL.

Para a área de planejamento e gestão das unidades familiares de produção e associações recebeu apoio da Associação Evangélica de Cooperação e Desenvolvimento EZE da Alemanha, cujos recursos, em sua maioria, eram oriundos de fundos públicos alemães, provenientes do Ministério do Exterior da Alemanha, cuja atenção voltava-se para os países considerados de terceiro mundo. Vale lembrar que a EZE cumpre, nestes tempos de globalização, os objetivos que a Igreja Mãe Luterana num outro momento da história cumpria. A Igreja Luterana, só teria sobrevivido dentro das circunstâncias do Estado brasileiro por manter os estreitos vínculos, inclusive jurídicos, com a Igreja Mãe da Alemanha. Desse vínculo fazia parte o envio de pastores, evangelistas, professores, diáconos e diaconisas, remessa de literatura e considerável auxílio financeiro (Vanderlinde, 2002).

As Escolas Comunitárias de agricultores ${ }^{14}$ recebiam apoio do Comitê Católico contra a Fome e pelo Desenvolvimento - CCFD - e da Evangélica Juventude Rural - ELJ. O primeiro, da França e o outro da Alemanha. Tais entidades da Europa e da América do Norte são organizações que arrecadam dinheiro através de campanhas e impostos nesses países e financiam projetos nos países em desenvolvimento.

Assim sendo, o Projeto Vida na Roça - PVR, considerado uma das propostas de maior repercussão no meio educativo por postular uma proposta de educação popular junto às escolas do campo pautada nos fundamentos de Paulo Freire, era mantido com recursos próprios e do Fundo de Crédito Rotativo, Associativismo e Luta pela Terra. Contava como agentes principais de fomento no período de 1996 a 2007 as Igrejas Católica e Protestante que, além de serem parceiras no desenvolvimento local e sustentável focavam a inclusão e o combate à miséria. 
O foco principal que justificou o aumento das políticas de investimento de tais instituições internacionais nas políticas de desenvolvimento da região Sudoeste do Paraná foi a construção de um Centro de Formação para viabilizar a preparação do homem do campo como cidadão com preparo técnico que permitisse trabalhar dentro das alternativas de sustentabilidade e respeito ao meio ambiente (ASSESOAR, 2007). O que denota que a organização, ao firmar cada parceria, buscava antecipadamente observar o caráter finalístico e os princípios base de cada entidade parceira, como forma de assegurar os princípios fins de acordo com o disposto pela Rede de informações para o terceiro setor RITS.

A parceria instituída com a Entidade Vastenaktie/CEBEMO, que representa a Igreja Católica da Holanda e financiava a educação para o desenvolvimento como parte de um processo de formação política, tinha por finalidade apoiar atividades em países em desenvolvimento destinadas à emancipação social e ao progresso econômico de grupos marginalizados. Portanto, pautava-se na visão de desenvolvimento consonante aos valores enfatizados pela doutrina social católica em relação ao ser humano e à sociedade.

No que se refere à Igreja Católica da França representada pelo Comitê Católico contra a Fome e pelo Desenvolvimento - CCFD - este financiou projetos de bolsas almejando educação para o desenvolvimento como forma de incentivo à mobilização da opinião pública em prol do combate às injustiças e pelo respeito aos direitos humanos dos povos. Também promovia cooperação com países em desenvolvimento, constituindo opinião pública ativa e desenvolvendo ações educativas. Tal solicitação dava-se em vista de compromisso permanente dos homens nas organizações e instituições que lutavam pelo desenvolvimento da humanidade, sempre visando o desenvolvimento humano e espiritual para todos.

A Igreja Evangélica da Alemanha, representada a princípio pela Associação Evangélica de Cooperação e Desenvolvimento - EZE - financiava projetos de desenvolvimento com fundos públicos alemães, ou seja, o Ministério Público da Alemanha voltado para o terceiro mundo. Ela tinha como princípio o trabalho de solidariedade e a construção de cidadania, fortalecendo o nível de engajamento social pela construção de uma sociedade mais justa.

Por outro lado, a Igreja Católica da Alemanha, representada pela Katholische Zentralstelle für Entwicklungshilfe - MISEREOR - auxiliava os membros mais fracos da sociedade, não importando se os necessitados fossem homens ou mulheres, qual a religião ou naturalidade. A dedicação ao próximo, uma atitude basilar da vida cristã, era o que organização visava exprimir em ação concreta.

Portanto, as organizações internacionais, bem como as nacionais, possuíam papel determinante nas bases financeiras e políticas da ASSESOAR considerando-se os inúmeros investimentos que recebia para a difusão de programas que incentivavam o desenvolvimento de formação de cunho técnico, educacional e de orientação ampliando as políticas voltadas para o homem do campo da região do Sudoeste do Paraná.

Conforme Miguel (2011, p. 04) "o contato com as fontes referentes à educação paranaense nos traz sentimentos. É este sentimento marcante que nos permite entender a singularidade das ações locais [...]" visto que elas se propõem, a partir da percepção de determinadas realidades, buscar apoio e incentivo que tornem possível a edificação de projetos. Tais projetos serviram para amenizar arestas expostas pelas lacunas de políticas de diferentes naturezas que se constituíram historicamente, mas que no caso relegaram aos homens do campo um lugar desprivilegiado de empoderamento necessário para inflamar as causas e ter tempo e espaço no meio ao qual pertencem. 


\section{Redefinições do perfil ideológico e de atuação da ASSESOAR}

Como já se fez considerações ao longo deste texto, a ASSESOAR sofreu inúmeras redefinições ao longo da sua história na perspectiva de se adaptar às transformações sociais, aos ditames do aparecimento dos diferentes processos produtivos no campo e às perspectivas de suas parcerias.

Assim sendo, o período histórico da sua origem, alongando-se até meados da década de 70, de conformidade com os seus Estatutos, foi marcado pelos caminhos delineados da Ação Pastoral da Igreja Católica, quando os principais cargos de direção não eram exercidos por agricultores e sim por religiosos e por profissionais liberais urbanos.

Porém, no final da década de 80 vislumbrou-se uma nova fase da instituição com o aparecimento dos movimentos sociais e sindicais na região. Esta fase é marcada pela atuação direta dos agricultores na direção da entidade, pela aproximação com os movimentos sociais e sindicais, assim como com o envolvimento na fundação do Partido dos Trabalhadores - PT.

Assim a ASSESOAR deixou de se constituir na única entidade a trabalhar em prol do desenvolvimento do homem do campo na região, desencadeando um processo que a levou a repensar seu espaço de atuação diante daquela realidade. A partir de então assumiu o entendimento de que os trabalhos de bases possuíam especializações e que os mesmos deveriam ser desenvolvidos em diferentes áreas, por diferentes instituições, e no todo trazendo contribuições para desenvolvimento da região. Coube-lhe, como entidade precursora de tal quadro, desenvolver um discurso de tradução das necessidades do homem do campo em meio à esfera onde o discurso político assumia lugar central no cenário. Por meio do desenvolvimento de uma agenda regional que predefinia os anseios do homem do campo da região, passou a se constituir na entidade porta voz e intérprete de questões agrícolas da região Sudoeste do Paraná.

Desencadeou com esse papel uma postura de esquerda, delineando um perfil ideológico que veio ao encontro das bases políticas do Partido dos trabalhadores - PT, o que marcou seu perfil atual em meio às lideranças municipais locais, sendo a maioria partidária de esquerda. Em contrapartida, o foco de atuação em meio ao homem do campo encontrou resistência por serem esses, em maioria, adeptos de linhas políticas conservadoras.

A ASSESOAR passou a ser considerada pelos agricultores, por técnicos que ali atuavam e pelas demais entidades que se desenvolveram nessa área como a "entidade mãe", por contribuir no desenvolvimento da maturidade política da região. Tal situação desencadeou um processo contraditório entre entender que a entidade possuía leitura política da região e que por outros delineamentos possuía um discurso considerado patrimônio moral, e elemento norteador para novas visibilidades de desenvolvimento regional do campo nesse meio.

Apesar do período de crise acompanhado de busca penosa de solução, a ASSESOAR administrou a importância da proliferação de inúmeras entidades na região como parceiras, o que lhe possibilitou a retirada do trabalho de massa, sem, contudo, deixar espaço vazio. Diante disso, lançou-se numa nova fase de desenvolvimento histórico, em que focou sua ação na tentativa de construir metodologias de intervenção apropriadas aos novos tempos.

Porém, pode-se considerar que as alterações econômicas que marcaram as décadas de 1980 e 1990, especialmente em relação ao perfil do processo produtivo do que se denominou de Revolução Verde, trouxeram desafios e inquietações para a agricultura familiar no Sudoeste do Paraná e com isto certa redefinição do perfil da atuação da 
ASSESOAR no sentido de buscar atualizar alguns aspectos da economia, da agroindústria e o desafio do processo de formação sócio territorial, vislumbrando-se assim um novo projeto, o do Projeto Vida na Roça - PVR.

Nesse processo de transição feito com determinada cautela, vislumbrou-se ações do novo projeto que, em 1996 no Município de Francisco Beltrão e em 2001 no Município de Dois Vizinhos, nasceu como PVR - com traço multidisciplinar, sendo o exemplo mais elaborado e proposto pela organização.

Importante para a consolidação de uma visão multidimensional de desenvolvimento que critica e supera a visão economicista e produtivista tão forte no campo e no meio popular mais amplamente, a entidade tornou-se referência nacional em termos de organização capaz de elaborar e experimentar alternativas de desenvolvimento integral no campo. O Projeto Vida na Roça - PVR, em dez anos de experiência, demonstrou ser um processo importante de resultados em termos de qualidade de vida no campo e de aprendizados quanto às estratégias interinstitucionais de promoção do desenvolvimento local. Ele não apenas se adequou a nova forma de trabalho, como conectou a entidade a um grande número de influências teóricas, constituindo-se em uma das primeiras experiências concretas e não massificadora da entidade.

O Projeto Vida na Roça propôs-se pensar atividades de desenvolvimento do homem do campo como sujeito partícipe do processo na condição de sujeito social. Nessa linha o PVR é analisado não como um projeto isolado ou fruto de demandas comunitárias, mas sim integrado a um amplo conjunto de cenários internos e externos à ASSESOAR, buscando construir um modelo educativo, vinculado à vida no campo, proposta essa que embasa os princípios dos movimentos sociais da Região Sudoeste.

Tal projeto constituiu-se, também, na dinâmica de desenvolvimento local/municipal da população do campo, iniciado nas escolas do campo, localizadas em diversas comunidades do Município de Francisco Beltrão, ainda no ano de 1996. Posteriormente, no ano de 2001, estendeu-se para as escolas do campo do Município de Dois Vizinhos. O projeto visou construir referências para o desenvolvimento do campo com base no que propõe a sua missão de desenvolver integralmente o homem:

[...] nos seus aspectos econômicos, social, político, cultural, educacional e humano, baseado em projetos localizados e estruturados a partir da organização local, da discussão dos problemas comunitários e na solução dos mesmos, fundamentados na cooperação e promoção da qualidade de vida e na perspectiva das políticas públicas (DUARTE, 2003, p. 103).

Fez-se presente a compreensão da necessidade de estabelecer relação entre desenvolvimento e educação, contrapondo-se a relação de subordinação, de fragmentação e de pouco acesso ao conhecimento universal a que a população do campo no Sudoeste do Paraná, foi historicamente condicionada.

A organização passou a reunir forças no sentido de fomentar o Projeto Vida na Roça englobando entidades a partir das diretrizes acordadas para o trabalho de desenvolvimento, o que remetia ao fortalecimento da dinâmica local e da autonomia da população. Assim, constituiu-se chave do desenvolvimento das comunidades, que pela lógica do Projeto desenvolvido com as entidades envolvidas e as comunidades, discutia e revisava o conceito de "desenvolvimento do campo", pensando em construir referência para um desenvolvimento de caráter solidário, comunitário e democrático, na perspectiva das políticas públicas de superação das lógicas da descontinuidade e da fragmentação (DUARTE, 2003, p. 59).

Assim, o projeto edificou-se, de um lado ancorado em reflexões ocorridas nos 
espaços das organizações do campo (associações, sindicatos e movimentos) de caráter popular que procuravam interpretar as dinâmicas produtivas, e de outro lado na perspectiva da geração, da apropriação da riqueza buscando compreender a atuação dos governos a partir das diretrizes do Estado na organização da sociedade. Assim, ao mesmo tempo em que teciam uma análise a respeito das dinâmicas sociais de produção e a apropriação do conhecimento pelas populações trabalhadoras, debatiam também o papel do conhecimento produzido pelas universidades para o desenvolvimento regional.

A falta perceptível de direcionamentos e de elementos argumentativos que demonstrem a real finalidade do processo educativo para a permanência e defesa de seu espaço foi - e é, em muitas vezes - atribuída como elemento motivador do desajuste da escola às necessidades locais que permite o constante abandono do campo pelo jovem (DUARTE, 2003). É neste espaço inicial de percepção e crítica que as lideranças foram desafiadas a percorrer uma trajetória diferenciada, que formulasse propostas duradouras e com capacidade de se refazerem permanentemente de forma alinhavada e participativa, gerando condição para maior capacidade de acompanhamento da relação necessária com o Estado, na busca do desenvolvimento regional por meio de um modelo educativo diferenciado.

Considerando a necessidade de refletir sobre os objetivos das condições atuais da educação de modo que os participantes pudessem expressar suas percepções, atentando às iniciativas já tomadas na escola a partir da avaliação dos alunos, estabelecia-se a primeira conversa e outras se sucederiam. As reflexões, então, seriam consideradas na prática pedagógica da escola e na formação dos professores.

Para efeito de organização dos debates que apontam para as questões da escola do campo, o conteúdo expresso pela população e pelos alunos foi categorizado, resultando na proposição de um trabalho didático pedagógico calcado na necessidade de compreender as questões didático-pedagógicas levantadas, sendo cogente ter presente esse elemento no ato da definição da linha de estudo com os professores atuantes no meio (ASSESOAR, 2007).

Perante tal quadro, por influência da organização cuja história institucional está significativamente calcada na trajetória da chamada Educação Popular, foi incorporada orientação distinta ao trabalho de repensar a escola no contexto do desenvolvimento do campo, a partir dos 'Temas Geradores', orientação derivada dos fundamentos de Paulo Freire.

Os agentes da organização envolvidos no processo tinham clareza da polêmica que esta metodologia geraria, podendo ser compreendida como ecletismo por causa do seu enquadramento por alguns autores como assentada no escolanovismo. Uma tensão estabeleceu-se entre as orientações, especialmente com alguns professores da Universidade Estadual do Oeste do Paraná - UNIOESTE, que defenderam a formação pelo viés da perspectiva histórico crítica. A justificativa da ASSESOAR veio pelo viés da opção pelos Temas Geradores e constituiu-se como elo entre a condição objetiva dos professores do campo quanto ao acesso ao conhecimento sistematizado, compreendendo-a como recurso para desinstalar e tencionar as condições pedagógicas da escola.

Nas falas da ASSESOAR (1990) estava presente a clareza de que os Temas Geradores constituíam um aporte metodológico válido para iniciar de forma mais frutífera, o repensar das escolas públicas do campo. Assim entendia-se que a reapropriação conceitual na perspectiva dialética estaria assegurada no processo do Programa de Formação de Professores do Campo, desenvolvido pelas universidades parceiras. De qualquer forma, havia tensão não resolvida e salutar devido ao fato de ter sido a primeira vez na história da educação da Região Sudoeste do Paraná que se ensejava o debate acerca das concepções pedagógicas de forma aberta e tematizada com professores. 
O conjunto de atividades realizadas teve como intencionalidade a tematização da escola, evidenciando diferentes percepções a respeito da escola entre os estudantes e seus pais. Isto tendo em vista a percepção distinta existente no campo entre valores das crianças e dos jovens em relação à população de mais idade, gerando assim tensão entre a percepção da secularização e o paradigma religioso, tencionando valores como obediência, respeito, trabalho, pecado, sexualidade, amor e culpa entre outras temáticas.

Assim sendo, a escola poderia assumir tarefa de vanguarda no sentido de tencionar pedagogicamente o terreno da construção social dos valores, por um lado em relação às determinações agrário-religiosas da população adulta do campo e, por outro, em relação aos valores liberais, expressos no discurso e nas práticas de vida de todas as faixas etárias da população.

Tornou-se evidente que se apropriar dos instrumentos que possibilitam a compreensão das relações entre educação e organização da sociedade pelo método dialético é um desafio de médio e longo prazo, que dependerá dos posicionamentos políticos e educativos pensados para o homem do campo a partir desse período.

A possibilidade está fortemente condicionada ao avanço da formação dos professores em determinada situação e, por outra, do suporte teórico e metodológico, permanentemente garantidos pelas organizações populares e/ou classe nas ações de desenvolvimento da população do campo e na relação com os governos.

A fecundidade de compreender e avançar na autonomia de tal população no contexto da sociedade está dialeticamente condicionada ao fato de que a Escola, ao trabalhar com a população do campo e ao formar professores para atuar no campo, colocase na perspectiva de atuar no avanço cultural, na acepção gramsciana:

O enorme desenvolvimento alcançado pela atividade e pela organização escolar
(em sentido lato) nas sociedades que surgiram do mundo medieval indica a
importância assumida no mundo moderno pelas categorias e funções intelectuais:
assim como se buscou aprofundar e ampliar a intelectualidade de cada indivíduo,
buscou-se igualmente multiplicar as especializações e aperfeiçoa-las. É este o
resultado das instituições escolares de graus diversos, inclusive dos organismos
que visam a promover a chamada alta cultura, em todos os campos das ciências e
da técnica (GRAMSCI, 1979, p.12).

A proposição tornou-se tarefa extremamente árdua pelo contexto de transformações necessárias e profundas na base produtiva que precisou generalizar-se para criar condições objetivas, de enriquecimento cultural, pela recriação das relações de trabalho, na perspectiva socialista.

Pelo viés e tal política, o Projeto Vida na Roça se faz um espaço de experimentação e reflexão sobre educação pública do campo, ensejando rica e frutífera relação com as escolas, os educadores, motivando os pais a participarem, os educadores a refletirem sobre o sentido dos conteúdos e metodologias tendo em vista o fortalecimento da vida e da cultura do campo em uma dimensão social e democrática.

Pelo processo de diversificação a ASSESOAR (1990), tornou-se referência metodológica na Região Sudoeste do Paraná e em demais regiões do país aonde as experiências chegaram por meio de escritos publicados pela própria organização. Os textos alavancaram iniciativas para a criação de cursos itinerantes de Licenciatura em Educação do Campo, pensados para formar educadores com concepção de formação que pensasse o homem do campo como sujeito de um processo à mercê das políticas públicas de ensino e aprendizagem.

Mesmo diante de inúmeros resultados de cunho inovador e desencadeados durante o processo, um limite metodológico importante a ser destacado foi a dificuldade de 
transpor, de forma integral, um programa educacional de desenvolvimento por uma organização de política pública pensada para as questões do campo de determinadas regiões do país. Organizações essas que primam por um conceito político que considere as particularidades dos sujeitos e não apenas a localização espacial e geográfica, pois a perspectiva da educação do campo se articula a um projeto ${ }^{15}$ político e econômico de desenvolvimento local e sustentável a partir da perspectiva dos interesses dos povos que nele vivem e anseiam por uma identidade sociocultural.

Schelling (1991) traz uma definição de cultura como práxis que pode ser útil à educação do campo. Para a autora,

[...] a capacidade do homem de se transformar e ser transformado é uma característica humano-genérica e essa capacidade está na base do conceito de cultura como práxis, por meio da qual [...] o homem não só se adapta ao mundo, como também o transforma (SCHELLING, 1991, p.32).

Tal transformação, pela perspectiva discutida, leva em consideração o nível da consciência e da interação comunicativa entre os indivíduos e sua organização social.

Experiências assim, que geram novos processos de referência, acabam desencadeando árduos embates no cenário político e social. E nem poderia ser diferente. Talvez o ponto crítico sobre a questão e de peso estratégico seja que a ASSESOAR e alguns de seus parceiros no Projeto Vida na Roça possuíam a percepção que o processo de desenvolvimento não considera a educação uma dimensão como as outras, mas como um componente decisivo para o avanço do processo sociocultural.

O cenário denotou que a organização por meio do PVR difundiu outra lógica de desenvolvimento pautada na perspectiva multidimensional, participativa, articulada, inclusiva e atuou no sentido de torná-la presente na vida cotidiana das famílias que dele participam considerando o ideário de uma sociedade diferenciada (ASSESOAR, 2007, p. 13). Constituiu, então, a grande diferença da organização de cunho popular ao arquitetar uma proposta a partir das práticas do homem do campo, adequando as realidades vividas pelos sujeitos, às propostas que venham ao encontro de suas necessidades.

Para o avanço das práticas pedagógicas voltadas para a educação do campo nas modalidades de educação básica e ensino superior por meio de Cursos de graduação itinerantes idealizados ${ }^{16}$, as propostas acenavam um contexto de maior amplitude no processo formativo do homem do campo pelo aprimoramento epistemológico e metodológico desenvolvido pela própria ASSESOAR na região.

\section{Considerações finais}

Os elementos que permitiram a organização da ASSESOAR - são utilizados para compor e estruturar uma visão específica da vida no campo, sedimentam e consolidam grande parte do repertório da educação do campo, da política e da ideologia da organização. É necessário notar que esses elementos pouco se alteraram desde a fundação da organização, porém, o aspecto mutável diz respeito à forma de leitura da realidade e ao modo de intervenção no espaço público.

Os obstáculos ideológicos que impediram a organização, de compreender o nível de convencimento sobre seu verdadeiro papel e missão em campos de luta pelo conhecimento e que elevaria o homem do campo a outro nível de percepção, se delineia pelas constantes alterações no sistema que acabam, por reflexo, reproduzindo o modelo que se contrapõe à ideologia libertadora. 
O caminho descrito e desenvolvido pela ASSESOAR e pelas instituições parceiras permite aqui afirmar que a imagem do projeto desenvolvido é o verdadeiro cenário de batalha, onde percepções de mundo lutam entre si para conquistarem espaços e compreenderem o fluxo da trajetória que envolve o campo. Diante um cenário complexo e que anda a passos lentos no processo de compreensão dos sujeitos envolvidos e das interfaces que se apresentam como forma de conexão dos diálogos em comum, torna-se pertinente perceber as transformações que implicam em reposicionamentos das relações que interligam mundos internos e externos e se influenciam mutuamente.

É notório que o processo não transcorreu de forma linear, mas sim, permeado por dúvidas e angústias, das quais algumas ainda permanecem. Todavia, o conjunto de posicionamento social e científico permite não apenas compreender o processo de forma profícua, mas entendê-lo como proposta coerente para a análise dos projetos de desenvolvimento de políticas que visam o aprimoramento da educação do campo. Ou seja, que tem como ponto central a questão do desenvolvimento do sujeito,

Objetivou-se, então, explicitar as redes de poder entre os sujeitos que colocam em prática projeto de desenvolvimento do campo, tendo como desafio, levar as comunidades a amadurecerem na capacidade e na autonomia diante das crises que a comunidade possa sentir de tempos em tempos, contribuindo para transformar as reflexões em ações concretas. Comprovou-se que a organização demonstrou capacidade de interpretar o cenário político e social da Região Sudoeste do Paraná, almejando articular: homens do campo, políticos, sociedade civil, sindicalistas e professores para agirem de acordo com os pressupostos e diluindo as responsabilidades das esferas decisórias no coletivo.

\section{REFERÊNCIAS}

ASSESOAR. Avaliação Final Projeto Vida na Roça. Francisco Beltrão - Paraná, 1998.

História da ASSESOAR. 1998a. Disponível em: http://assesoar.org.br/?page id=25. Acesso em 20/09/2014.

FACIBEL, STRs. 1957-1997: a Revolta dos Colonos. De olho no passado e pés no futuro. Francisco Beltrão: Grafit, 1997.

. 25 anos construindo Alternativas Populares. Francisco Beltrão, PR, 1990

2014). 2010.

. Plano Trienal 2011 - 2014 (01 de março de 2011 a 31 de dezembro de

. Relatório de Avaliação da ASSESOAR. Francisco Beltrão - PR, 2007. Disponível em: assesoar.org.br/arquivos/TAP000051.htm \# acesso 10/07/2011.

DUARTE, V.P. Escolas públicas no campo, problemáticas e perspectivas: um estudo a partir do Projeto Vida na Roça. Francisco Beltrão: ASSESOAR, 2003.

GOMES, Iria Zanoni. 1957: a Revolta dos Posseiros. Curitiba: Criar Edições Ltda., 1986. 
GRAMSCI, A. Caderno 12: apontamentos e notas esparsas para um conjunto de ensaios sobre a história dos intelectuais. $101 \mathrm{p}$. Tradução, apresentação e comentário de Paolo Nosella. São Carlos: UFSCAR, 1979. Documento Inédito.

JOÃO XXIII, SUA SANTIDADE. Carta Encíclica Mater Et Magistra - 1961: a recente evolução da questão socialà luz da doutrina cristã Disponível em: http://www.vatican.va/holy_father/john_xxiii/encyclicals/documents/hf_jxxiii_enc_15051961_mater_po.html. Acesso em: 20/09/2014.

MARX, K.; ENGELS, F. A ideologia alemã (Feuerbach). 11 ed. São Paulo: Hucitec, 1999. [tradução de José Carlos Bruni e Marco Aurélio Nogueira].

MIGUEL, Maria Elisabeth Blanck. A formação do professor para as escolas rurais no Paraná no contexto das políticas de educação nacionais e internacionais. Revista HISTEDBR On-line, Campinas, n.43, p. 21-31, set2011 - ISSN: 1676-2584

RITS. Rede de informações para o terceiro setor. Disponível em: <http://www.rits.org.br/gestao_teste/ge_testes/ge_mat01_aginter.cfm \#>. Acesso em: 10/07/2011.

SCHELLING, Vivian. A presença do povo na cultura brasileira. Campinas: Editora da UNICAMP, 1991.

Vanderlinde, Tarcísio. A construção de uma nova paisagem. Revista Varia Scientia. v. 02, n. 02, p. 143-152, 2002.

VERONESE, Claudino Domingos. O papel pedagógico da ASSESOAR no apoio à construção da cidadania dos ex-posseiros do Sudoeste do Paraná. Dissertação (Mestrado em Educação), Universidade de Ijuí. Ijuí/RS, 1998. 244p.

WACHOWICZ, Ruy Christovam. Paraná, Sudoeste: ocupação e colonização. Curitiba: Lítero Técnica, 1985.

\section{Notas}

${ }^{1}$ Associação de Estudos, Orientação e Assistência Rural (ASSESOAR)

${ }^{2}$ UNOCHAPECO / PUCPR mzrotta@gmail.com

\footnotetext{
${ }^{4}$ Composto por 37 jovens, militantes da Juventude Agrária Católica - JAC, muitos continuam ainda hoje engajados nas lutas desencadeadas por essa ONG em prol do desenvolvimento do Homem do campo nessa região.

${ }^{5}$ Que incentivou a migração para essa região de pequenos agricultores provenientes basicamente dos Estados de Santa Catarina (18,9\%) e Rio Grande do Sul (58\%), descendentes de imigrantes de países europeus, principalmente Itália (40\%), Alemanha (13\%) de outros países europeus (24\%). Apenas $18 \%$ se declararam de origem luso-brasileira ("caboclos", na maioria). (GOMES, 1986)

${ }^{6}$ Em 1957, o Sudoeste paranaense foi palco de intenso conflito pela posse da terra, envolvendo posseiros, companhias colonizadoras e o poder público. O conflito teve origem na disputa jurídica pela posse da gleba MISSÕES e parte da gleba CHOPIM. O governo federal, através da Colônia Agrícola Nacional General Osório - CANGO, implantou na região projeto de colonização e incentivou gaúchos e catarinenses para
} 
povoá-la. A companhia colonizadora Clevelândia Industrial e Territorial Ltda - CITLA, formada por particulares, igualmente instalou-se na área na condição de herdeira das glebas, resultado de longo processo judicial envolvendo o poder público e empreendedores particulares. O conflito pela posse da terra estendeuse pelos atuais municípios de Capanema, Dois Vizinhos, Francisco Beltrão, Pato Branco, Pranchita, Santo Antonio do Sudoeste, Verê e foi concluído com a vitória dos posseiros, que tiveram suas posses regularizadas e tituladas a partir de 1962 (WACHOWICZ, 1985).

${ }^{7}$ É um amplo programa idealizado na década de 70 para aumentar a produção agrícola no mundo por meio do melhoramento genético de sementes, uso intensivo de insumos industriais, mecanização e redução do custo de manejo.

${ }^{8}$ Com base na Doutrina Social da Igreja.

${ }^{9}$ Mesmo que fortemente eivada de elementos doutrinais.

${ }^{10} \mathrm{O}$ mundo (natureza, sociedade) sempre foi modificado pelas ações humanas e naturais, gerando processos organizativos que mexem na relação das pessoas entre si e delas com a natureza. Essas mudanças são decididas conscientemente ou não, para satisfazer necessidades físicas ou inventadas socialmente; A satisfação das necessidades e anseios dos seres humanos, quando não orientadas por valores solidários das relações humanas e naturais tornam-se insensíveis e violentas, podendo destruir desde a harmonia entre as pessoas até a própria vida, sem falar da natureza como um todo; A forma como estão estruturadas as organizações que regulam as relações entre as pessoas e destas com o mundo, podem reforçar ou alterar traços da cultura produzida historicamente. O que realmente faz a diferença em termos de capacitação das pessoas é se elas são passivas ou se elas são criativas. Passivas: fruto da visão de que as coisas já estão prontas ou cabe a outros fazer. Criativas: compreendendo que nada está parado, tudo está constantemente sendo recriado e qualquer pessoa ou organização é desafiada para tal; A sociedade estrutura-se e mantém seu movimento pelo confronto de interesses, vontades, idéias, conhecimentos e papéis sociais diferenciados e dinâmicos (ASSESOAR, 1998a).

${ }^{11}$ Relacionada com a continuidade dos aspectos econômicos, sociais, culturais e ambientais da sociedade humana.

${ }^{12}$ E visualizando a necessidade de se manter devido à falta de apoio do Estado e por contribuir nas políticas que combatem o comunismo, abre-se um novo modelo denominado "Igreja dos pobres", criado no pontificado de João XXIII, pautada na visão da Igreja como congregação de fé (ASSESOAR, 1998a).

${ }^{13}$ Há mais de 50 anos, MISEREOR está comprometida com a luta contra a pobreza na África, Ásia e América Latina.

${ }^{14}$ Que priorizam os aspectos tecnológicos e de gestão sistêmica das unidades produtivas, propondo-se aumentar a eficiência produtiva do sistema (produtos) tradicional da região. Para não comprometer o custo de produção, propõe o uso de recursos da propriedade e tecnologias tradicionais, porém com gestão racional e sistêmica dos recursos da propriedade e dos recursos do saber que adquirirão numa concepção agroecológica, portanto, alternativa ao modelo dominante na região e consagrador da tradição da ASSESOAR (ASSESOAR, 1998a).

${ }^{15}$ Nas teses sobre Feuerbach, Marx (1999, p. 126) afirma que "é na práxis que o homem deve demonstrar a verdade, isto é, a realidade e o poder, o caráter terreno de seu pensamento". Ele faz a crítica à doutrina materialista tradicional, para a qual os homens seriam produto das circunstâncias e da educação, bem como, que os homens transformados seriam produtos de outras circunstâncias e de uma educação modificada. Destaca que o materialismo tradicional "esquece que são precisamente os homens que transformam as circunstâncias e que o próprio educador deve ser educado". Nestes parâmetros percebe-se que a práxis passa ser condição para a ação revolucionária, de modo que os homens podem pensar o sentido de suas atividades, e sua organização política por meio de ações conjuntas na luta contra a opressão. Sendo que a educação do campo está posta como um desafio ao considerar a cultura dos povos do campo em sua dimensão empírica e fortalecer a educação escolar como processo de apropriação e elaboração de novos conhecimentos. E o fator de maior relevância neste contexto é que a população do campo do Estado do Paraná sinaliza uma diversidade não encontrada em outros Estados, e as escolas do campo desse meio terão presente no seu interior essa conflituosa, mas, portanto rica diversidade sociocultural e política.

${ }^{16}$ Pós - Médio Curso de Graduação em Pedagogia da Terra (UNIOESTE) e o de Licenciatura em Educação do Campo (UTFPR, Campus de Dois Vizinhos - PR). 